\title{
Relationship between heterozygosity and asymmetry: a test across the distribution range
}

\author{
SALIT KARK* $\dagger \$$, URIEL N. SAFRIEL $¥$, CRISTIANO TABARRONI§ \& ETTORE RANDI§ \\ $\dagger$ Department of Biological Sciences, Stanford University, Stanford, CA 94305-5020, U.S.A., $\ddagger$ Department of \\ Evolution, Systematics and Ecology, The Silberman Institute of Life Sciences, The Hebrew University of Jerusalem, \\ Jerusalem 91904, Israel and §/stituto Nazionale per la Fauna Selvatica, via Ca' Fornacetta 9, 40064, \\ Ozzano dell'Emilia (BO), Italy
}

\begin{abstract}
The genetic basis of developmental stability, as measured by bilateral asymmetry, has been debated for over 50 years among developmental and evolutionary biologists. One of the central theories dealing with this relationship suggests that higher levels of genetic diversity, as reflected in heterozygosity, result in increased stability during development and thus in lower asymmetry. In this study, we aimed to test the relationship between asymmetry and heterozygosity at two levels: (1) the population level, where mean heterozygosity within a population is predicted to be negatively correlated with mean population asymmetry and (2) the individual level, where the proportion of heterozygous loci of an individual and its bilateral asymmetry estimates are predicted to be negatively correlated. While previous studies often focused on local populations, work across species ranges can answer the following questions. Are levels of heterozygosity correlated with levels of developmental instability, as estimated by bilateral asymmetry? Are patterns consistent across the distribution range, from the periphery towards the core? Does the relationship between genetic stress and bilateral asymmetry depend on the degree of environmental stress? We tested heterozygosity levels in 26 loci and asymmetry in third toe length in 11 populations of the chukar partridge (Alectoris chukar) across a sharp climatic gradient in Israel from the arid periphery, through the Mediterranean-desert ecotone towards the Mediterranean areas located further away from the range boundaries. Genetic diversity, as estimated using both observed and expected heterozygosity, was not associated with asymmetry at either the population or at the individual level. Whereas heterozygosity showed a hump-shaped pattern, peaking at the ecotone, asymmetry monotonically increased towards the range periphery. We argue that whereas asymmetry may serve as a useful tool for estimating changes in environmental stress, it may not be widely applicable for estimating genetic stress.
\end{abstract}

Keywords: Alectoris chukar, bilateral asymmetry, developmental instability, distribution range, heterozygosity, peripheral populations.

\section{Introduction}

The relationship between heterozygosity and developmental instability, as estimated by the levels of bilateral asymmetry, has been debated for over five decades (Clarke, 1993; Markow, 1995). The two most common mechanisms explaining the maintenance of developmental stability have a genome-wide basis (Clarke, 1998). They include: (1) the Genomic Coadaptation Theory, which predicts that more balanced coadapted gene complexes (i.e. groups of interacting loci) will show higher stability in development and therefore lower

*Correspondence. E-mail: salit@stanford.edu asymmetry (reviewed in Clarke, 1993; Markow, 1995), and (2) the Heterozygosity Theory, predicting that levels of protein heterozygosity will be inversely correlated with levels of bilateral asymmetry (Lerner, 1954). The latter theory argues that heterozygosity has a buffering role by increasing biochemical diversity and thus enabling a dynamic stable developmental pathway in changing environments (Mayr, 1970; Livshits \& Smouse, 1993a).

\section{Bilateral asymmetry}

Fluctuating asymmetry (FA) is the unsigned difference between the two sides of a bilaterally symmetrical 
morphological trait (Ludwig, 1932). It is considered a useful indicator of developmental instability and environmental stress (Van Valen, 1962; Leary \& Allendorf, 1989) reflecting the ability of an organism to carry out symmetrical development of bilateral traits in the face of environmental and genetic stress. Genetic stress may include the loss of genetic diversity due to inbreeding and genetic drift, as well as disruption of coadapted gene complexes (see Clarke, 1995; Brookes et al., 1997; Møller \& Swaddle, 1997 for discussion). As the development of both sides of a bilaterally symmetrical trait is presumably under the influence of a single set of genes (Clarke, 1993; Markow, 1995; Møller \& Swaddle, 1997), differences in asymmetry between the two sides of the body represent variation of environmental origin (Palmer \& Strobeck, 1986; Clarke, 1993). However, the tendency to develop in a stable path and to exhibit asymmetry may be influenced by genetic factors (Palmer \& Strobeck, 1986; Møller \& Swaddle, 1997). Two other major forms of asymmetry exist, including directional asymmetry (DA) where one side of the body is consistently larger than the other, and antisymmetry, where most individuals deviate from symmetry towards either the right or left sides. These have not been considered as reliable indicators of developmental instability due to their unknown heritable component (Van Valen, 1962; Palmer \& Strobeck, 1986; Leary \& Allendorf, 1989). Yet increasing evidence suggests that a continuum between the different types of asymmetry exists and that DA and antisymmetry, in addition to FA, may often reflect the ability to carry out identical development of bilateral traits in the face of stress (Graham et al., 1993, 1998).

\section{The Heterozygosity Theory: population and individual level}

Whereas a test of the Genomic Coadaptation Theory is difficult, empirical examination of the Heterozygosity Theory is more straightforward. The latter theory may be tested at two levels: (1) the population level, where mean population heterozygosity is predicted to be negatively correlated with mean population asymmetry; and (2) the individual level, where the proportion of heterozygous loci of an individual is predicted to be negatively correlated with its degree of asymmetry. There is evidence supporting the Heterozygosity Theory (e.g. Kat, 1982; Leary et al., 1985; Siikämaki \& Lammi, 1998), as well as opposing it (Livshits \& Smouse, 1993b; Woolf, 1993; Britten, 1996; Møller, 1998), mostly at the population level (Clarke, 1993). A recent meta-analysis of 41 studies testing the relationship between FA and heterozygosity showed that only a very small proportion of the variance in developmental instability, as estimated by FA, was explained by heterozygosity levels (Vøllestad et al., 1999). Vøllestad et al. (1999) discuss the prediction that the association between FA and heterozygosity will be more important in stressful compared with more benign environments. Under this prediction, populations near the periphery of a species' range will show a stronger correlation between developmental stability and heterozygosity compared to populations from less marginal environments.

We suggest that a comparison of this relationship at both the individual and population level across a species' range, from core to periphery is strongly needed, and may help resolve some of the contradictions appearing in the literature. Work across a species range provides a unique opportunity to test this interaction in relation to ecological and environmental changes. It also allows us to test the hypothesis that the association between heterozygosity and developmental stability is stronger in the more stressful parts of the range, near the periphery, compared to the interior of the range. This hypothesis predicts that the magnitude of the association between genetic diversity and developmental instability will depend on the levels of environmental stress experienced by individuals.

In this work, we aim to test the association between bilateral asymmetry and genetic diversity across a steep climatic and distribution gradient in Israel, from the core towards the periphery of the range. Focusing on the chukar partridge (Alectoris chukar) we test the following hypotheses:

1 Mean heterozygosity and mean asymmetry are negatively correlated at the population level;

2 The proportion of heterozygous loci of an individual and its degree of asymmetry are negatively correlated; 3 The relationship between heterozygosity and asymmetry depends on the location of the populations across the distribution range, from core to periphery.

\section{Materials and methods}

\section{The chukar partridge}

The chukar, a bird of the phasianid family, is distributed in Israel across a sharp climatic cline from Mediterranean regions in the north, where mean annual rainfall is between 450 and $1000 \mathrm{~mm}$, to extremely arid areas only $\sim 200 \mathrm{~km}$ away in the Negev Desert, where mean annual rainfall is less than $50 \mathrm{~mm}$ (Bitan \& Rubin, 1991). In the arid areas of the southern Negev desert the chukar reaches the southern limit of its global distribution range (see range periphery marked in Fig. 1; Shirihai, 1996). An especially steep part of the rainfall gradient occurs in the northern Negev ecotone (i.e. area of transition) between Mediterranean and desert ecosystems, where within a belt of less than $60 \mathrm{~km}$, annual rainfall decreases 


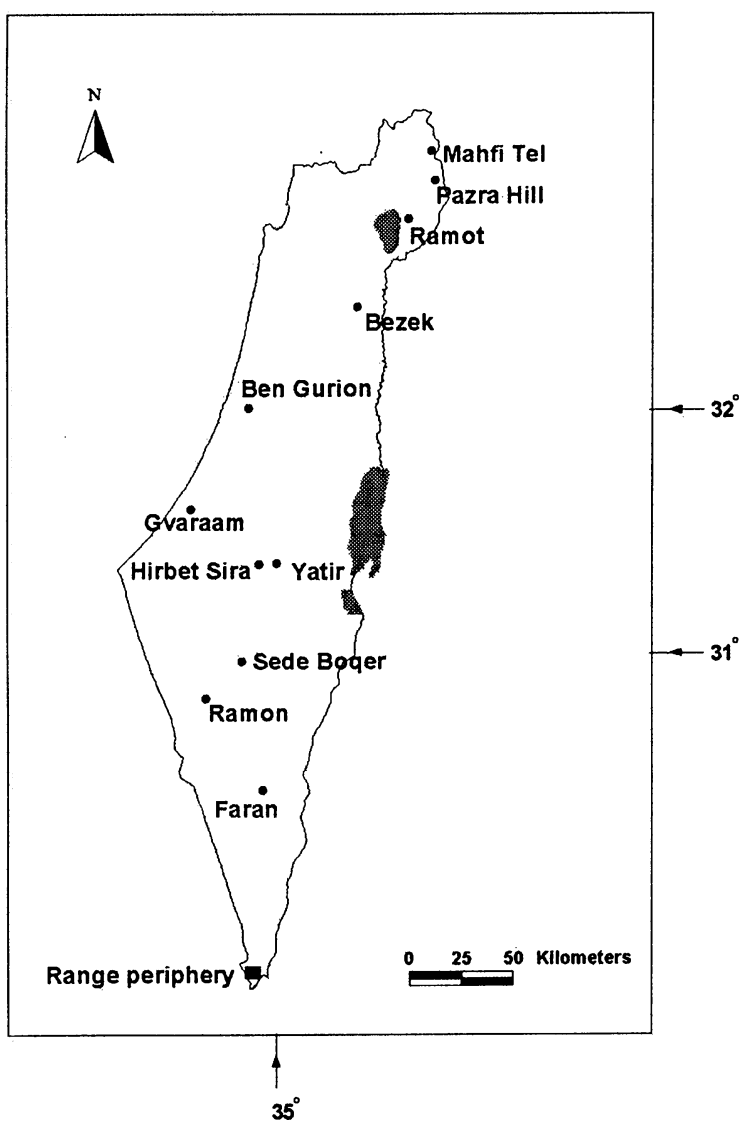

Fig. 1 Map of chukar populations sampled in the study. Range periphery (marked by a square) was determined as the centre of the grid where population distribution decreased to zero following Shirihai (1996).

from 450 to $150 \mathrm{~mm}$ and its spatio-temporal variability largely increases (Bitan \& Rubin, 1991, and the Israel Meteorological Service). From the ecotone towards the desert, distribution becomes patchy and populations become small and discontinuous (Shirihai, 1996; Kark et al., 1999). This climatic cline is associated with a change in phytogeography from largely Mediterranean to largely Saharo-Arabian vegetation, with a combination of both in the ecotone region (Danin \& Plitman, 1987; Kark, 1999). The chukar is sedentary across its Eurasian range and does not exhibit known latitudinal or altitudinal migration (Shirihai, 1996).

\section{Population sampling and genetic analysis}

Eleven chukar populations were sampled across Israel from the northern Golan to the southern Negev desert (Fig. 1). Populations were carefully selected from open areas, which had been closed to hunting during the past decades, and were over $10 \mathrm{~km}$ away from agriculture, irrigation or settlements. Population was defined based on area size $\left(\sim 10 \mathrm{~km}^{2}\right)$. The two most distant populations were located $322 \mathrm{~km}$ away from one another (Fig. 1). Populations were initially pooled into three distribution regions, which included the Mediterranean core, the ecotone and the arid periphery for analysis purposes (Table 1). Birds were hunted by the Israel Nature Conservation and National Park Authority rangers and authorized hunters during the nonbreeding season of autumn-winter 1995-6. Heart and liver tissues were dissected from birds in the field, stored in ice coolers, and transferred within several hours to laboratory freezers kept at $-20^{\circ} \mathrm{C}$ or $-80^{\circ} \mathrm{C}$. Samples of each tissue were separately homogenated and clear supernatants were collected and stored at $-80^{\circ} \mathrm{C}$ in aliquots. Polyacrylamide gel electrophoresis, staining of allozyme products and genetic interpretation of electromorph mobility were performed following Randi \& Alkon (1994). Twenty-six putative loci were resolved, of which nine were polymorphic (see Randi \& Alkon, 1994 for list of loci, except PEP-2, LDH, SOD-2, $m G O T, m I D H$ and $G D H$ that were not resolved here). Estimates of heterozygosity, including observed (direct count) and expected heterozygosity (unbiased estimate based on HardyWeinberg equilibrium) were computed for each population using BIOsYs-1, v.1.7 (Swofford \& Selander, 1989).

\section{Estimation of asymmetry}

The length of the right and left third toe, from joint to digital tip, was measured on all individuals in the field, except for individuals from Bezek and Ben-Gurion Airport, which were measured in the laboratory. The third toe length is related to locomotion, a highly important activity for this phasianid species that spends much of its daily foraging activity walking (Alkon, 1974). Toe length was selected because it had the highest repeatability of several traits preliminarily measured on a sample of individuals from Ben-Gurion Airport (including wing and tarsus length). Measurement repeatability was estimated by measuring both sides of the body of 10 individuals and then re-measuring the same set of individuals (giving a total of 40 measurements; see Siikämaki \& Lammi, 1998). We further analysed repeatability using a mixed-model analysis of variance with factors Individual (I), Side (S) and Replicate (R) following Swaddle et al. (1994). In this model, the ratio between MS $(\mathrm{I} \times \mathrm{S})$ and the combined MS $(\mathrm{I} \times \mathrm{S} \times \mathrm{R})$ and $\mathrm{MS}(\mathrm{I} \times \mathrm{R})$ provides an $F$-test for evaluating whether between-individual variation in estimated asymmetry is significantly larger than can be accounted for by measurement error taking into account session bias (Swaddle \& Cuthill, 1994; David et al., 1999). All measurements were taken by the same worker (S.K.) using a metal ruler to an accuracy of $0.1 \mathrm{~cm}$. 
Table 1 List of chukar partridge populations studied in Israel, shown from north to south; distribution area; mean observed and Hardy-Weinberg expected heterozygosity levels; mean sample size per locus in genetic diversity analyses; mean asymmetry calculated as mean unsigned right-minus-left $(\mathrm{R}-\mathrm{L})$ measurements; the percentage of individuals that were symmetrical in the population; and sample sizes in the asymmetry calculations. See Fig. 1 for population locations

\begin{tabular}{llcccccc}
\hline Population & Area & $\begin{array}{c}\text { Mean } \\
\text { observed } \\
\text { heterozygosity }\end{array}$ & $\begin{array}{c}\text { Mean } \\
\text { expected } \\
\text { heterozygosity }\end{array}$ & $\begin{array}{c}\text { Mean } \\
\text { sample size } \\
\text { per locus }\end{array}$ & $\begin{array}{c}\text { Mean } \\
\text { unsigned } \\
\text { R - L }\end{array}$ & $\begin{array}{c}\text { Sample size } \\
\text { individuals }\end{array}$ & $\begin{array}{c}\text { Sor FA } \\
\text { calculation }\end{array}$ \\
\hline Mahfi Tel & Med. & 0.052 & 0.069 & 27 & 0.013 & 87.50 & 23 \\
Pazra Hill & Med. & 0.063 & 0.076 & 24.7 & 0.038 & 72.22 & 16 \\
Ramot & Med. & 0.079 & 0.080 & 24.1 & 0.000 & 100.00 & 22 \\
Bezek & Med. & 0.086 & 0.094 & 17.5 & 0.032 & 75.00 & 19 \\
Ben Gurion & Med. & 0.093 & 0.105 & 24.7 & 0.033 & 66.66 & 21 \\
$\quad$ Airport & & & & & & & \\
Gvaraam & Ecotone & 0.120 & 0.115 & 25.9 & 0.040 & 58.33 & 24 \\
Yatir & Ecotone & 0.106 & 0.107 & 19.8 & 0.026 & 78.95 & 19 \\
Hirbet Sira & Ecotone & 0.103 & 0.107 & 28.7 & 0.070 & 33.33 & 30 \\
Sede Boqer & Arid & 0.073 & 0.096 & 27.6 & 0.100 & 14.81 & 27 \\
Ramon & Arid & 0.096 & 0.100 & 31.7 & 0.111 & 29.63 & 28 \\
Faran & Arid & 0.094 & 0.105 & 25.8 & 0.094 & 12.50 & 23 \\
\hline
\end{tabular}

Med., Mediterranean.

Locations were sampled in a random order relative to the north-south distribution gradient to avoid a potentially confounding bias stemming from the increasing experience of the measurer over the course of the study. Only adult (non-juvenile) birds were included in the analyses. Juveniles were identified based on feather colour patterning (Alkon, 1979).

Asymmetry was calculated in several ways: First, asymmetry was estimated in each of the populations using the mean of the unsigned R - L-value (FA1 of Palmer, 1994). Following, the proportion of symmetrical individuals in each population was calculated and compared across the distribution range. An individual was considered symmetrical if the value of its $R-L$ subtraction was zero. This measure does not reflect the size of asymmetry but rather its proportion in a population, and is useful as a relative measure for comparison among populations. Comparisons were further done across the three predetermined areas, to obtain larger sample sizes. Asymmetry was estimated for each of the three regions using the mean unsigned $\mathrm{R}-\mathrm{L}$ (Palmer, 1994).

Distribution of signed right-minus-left $(\mathrm{R}-\mathrm{L})$ values over all individuals $(n=252)$ was drawn and normality of the distribution was examined using the ShapiroWilk $W$-test (JMP 3.1.5). To test for normality of the distributions for each of the areas, the skewness and kurtosis of the signed $\mathrm{R}-\mathrm{L}$ were calculated and the distribution was inspected across the three areas following Palmer (1994). Directionality in asymmetry was tested in each of the three areas using a Wilcoxon signed-rank test for deviation of the median from zero.
This aimed to reveal whether the median of $\mathrm{R}-\mathrm{L}$ changes across the species' range. The statistical significance was estimated for each area following a Sequential Bonferroni Correction (Rice, 1989). As mean body size did not increase from the core towards the periphery, and was not positively correlated with mean levels of asymmetry (Kark, 1999), we did not need to use a weighted estimate of asymmetry, such as FA3 of Palmer (1994).

\section{Relationship between genetic diversity and asymmetry}

Population level A linear regression was performed between: (1) mean observed heterozygosity in a population and its mean unsigned $\mathrm{R}-\mathrm{L}$ calculated for the two sexes pooled and weighted by their relative frequency; (2) mean heterozygosity and the percentage of individuals within each population that were symmetrical (i.e. had R - L values equal to zero). A regression was also performed following an arcsine transformation for the percentage of symmetrical individuals and for heterozygosity. This was done for both the observed and the Hardy-Weinberg expected heterozygosity. In these calculations, all individuals for which asymmetry or genetic diversity estimates were available were included $(n=252)$.

A regression was performed between the observed heterozygosity and mean asymmetry across all populations for each of the nine polymorphic loci separately. In this case, $P$-values were calculated following a Sequential Bonferroni Correction. 
Individual level Regression between the proportion of the loci in which an individual was heterozygous and the unsigned $\mathrm{R}-\mathrm{L}$ asymmetry estimate of the same individual was obtained. This association was only examined in individuals for which both estimates were available $(n=247)$. A similar regression was performed following an arcsine transformation for the percentage of heterozygous loci for each individual. This was also calculated for each of the 11 study populations separately. Similar trends were found in males and females (not shown). Therefore, in order to enlarge sample sizes, the two sexes were combined for further analyses.

A test across the range To test whether the asymmetryheterozygosity relationship is dependent on the location of the population across the range, from core to periphery, we tested the relationship at the individual level within each population separately. In addition, we explored whether partial sampling of the distribution range could have led to different patterns by analysing this relationship first for the part of the range from periphery to ecotone alone, without including the core, and then for the section from the ecotone to the core alone, excluding the periphery of the range. The above analysis was done to emphasize the potential limitations related with partial sampling of the range and therefore the same data points from the ecotone were used in both cases.

\section{Results}

\section{Association at the population level}

Mean observed heterozygosity was not associated with mean asymmetry when tested across all 11 study populations (Table 1); $r^{2}$ was low $\left(r^{2}=0.046, P=0.52\right.$; Fig. 2a). In addition, the regression between mean heterozygosity and the percentage of symmetrical individuals (PS) was not significant and showed an $r^{2}$ of $0.074(P=0.42)$. These patterns were maintained after an arcsine transformation of the data $\left(r^{2}=0.056\right.$, $P=0.49$ for heterozygosity vs. mean FA and $r^{2}=0.083, P=0.39$ for heterozygosity vs. PS). Regression between mean expected heterozygosity and mean FA was not significant and showed similar trends to those revealed between mean observed heterozygosity and mean FA $\left(r^{2}=0.18, P=0.19\right)$. This was maintained after an arcsine transformation of the heterozygosity means.

Partial sampling of the species' range in Israel could have led to detecting different patterns: When analysed for the less marginal regions, from the core to the ecotone alone (eight populations), a positive but nonsignificant relationship was found between heterozygosity and mean asymmetry $\left(r=0.48, r^{2}=0.23, P=0.23\right.$; Fig. 2b). When only populations from the ecotone to the periphery were included (six populations) the relationship was again non-significant yet was negative $\left(r=-0.73, r^{2}=0.54, P=0.1\right.$; Fig. $2 \mathrm{c}$ ).

Regression between observed heterozygosity and mean FA calculated for each of the nine polymorphic loci separately was not statistically significant for any of the loci. In all cases (bar $A d h), r^{2}$ was $<0.22$ and $P>0.15$. For $A d h$, the $P$-value for this regression was 0.03 , yet this result was not statistically significant following a Sequential Bonferroni Correction.

\section{Association at the individual level}

A similar pattern was found at the individual level: The regression between the proportion of heterozygous loci for each individual and its unsigned $\mathrm{R}-\mathrm{L}$ value showed an $r^{2}$ of $0.0029(P=0.40)$. The relationship remained similar after an arcsine transformation $\left(r^{2}=0.004\right.$, $P=0.32$ ). When tested within each of the study
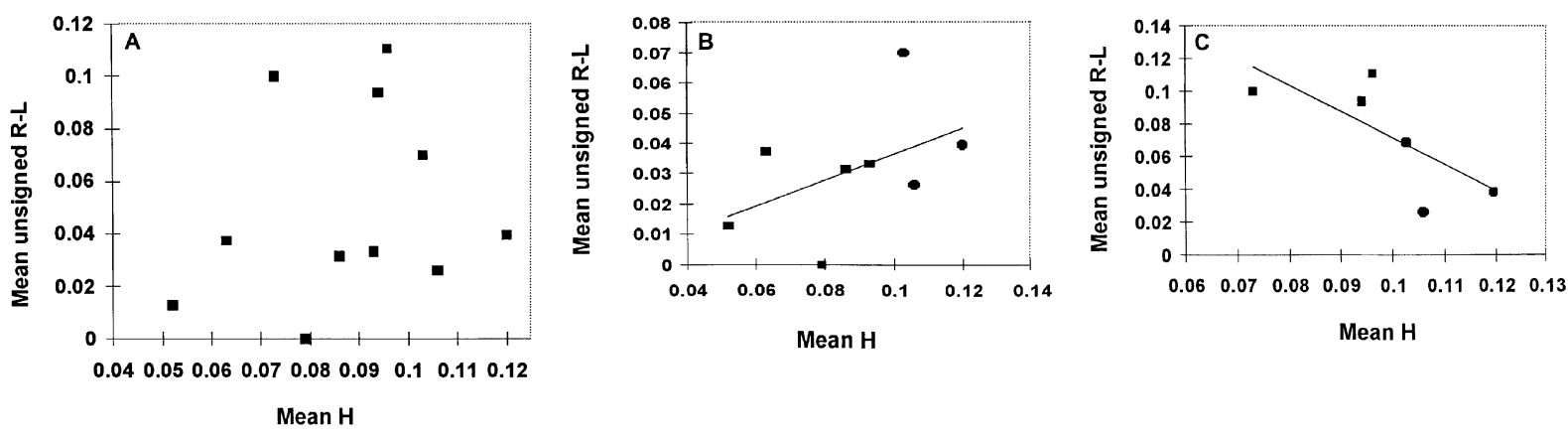

Fig. 2 Relation between mean observed heterozygosity and mean fluctuating asymmetry (FA) in 11 study populations across the chukar range in Israel from core through ecotone to periphery (A); from core (squares) to ecotone (circles) only (B); from the ecotone (circles) to the extreme periphery (squares) only (C); and with linear regression plots for $\mathrm{B}$ and $\mathrm{C}$.

(C) The Genetics Society of Great Britain, Heredity, 86, 119-127. 
populations, there were no significant relationships between the proportion of heterozygous loci of an individual and its levels of asymmetry $\left(r^{2}<0.1\right.$, $P>0.1$ in all 11 cases).

\section{Trends in diversity and in asymmetry across the chukar range}

Mean observed heterozygosity showed a unimodal pattern across the range. A quadratic regression between mean heterozygosity levels in the population and distance of the population from the range periphery was significant for both observed $\left(r^{2}=0.70, P=0.0025\right.$; Fig. 3) and expected heterozygosity based on HardyWeinberg equilibrium $\left(r^{2}=0.83, P=0.0001\right)$. Diversity peaked at the Mediterranean-desert ecotone, and decreased monotonically towards the core and nonmonotonically towards the extreme periphery of the chukar range (Kark et al., 1999; Kark, 1999). However, asymmetry showed a different pattern across the chukar range. The proportion of symmetrical individuals in the population was significantly correlated with the distance of the population from the range periphery (Spearman Rho $=0.85, P<0.001$; sexes pooled). Consistent results were found for the correlation between the distance of population from the range periphery and mean unsigned $\mathrm{R}-\mathrm{L}$ for both sexes (Spearman Rho $=-0.81$, $P<0.0026$ for males and $-0.82, P<0.0021$ for females; see Fig. 3 for sexes pooled).

The mixed-model ANOvA with factors Individual (I), Side (S) and Replicate (R) showed an $F_{9,18}=8.056$

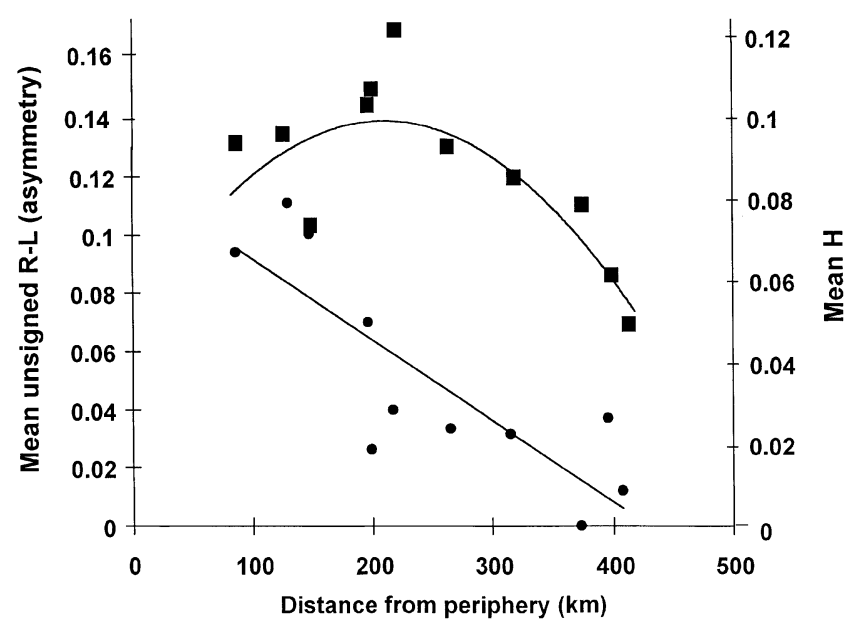

Fig. 3 Trends in mean observed heterozygosity (H; squares) and in mean asymmetry (circles) vs. distance of population from chukar range periphery in Israel. A linear regression line is fitted to the asymmetry vs. distance plot and a quadratic regression to the heterozygosity vs. distance plot.
$(P<0.0001)$ suggesting high repeatability for the measurement of the third toe.

\section{Shifts in bilateral asymmetry}

As the degree of asymmetry increased from the core towards the periphery of the range, a directional asymmetry component (towards a negative $\mathrm{R}-\mathrm{L}$ ) appeared. Although the distribution of signed $\mathrm{R}-\mathrm{L}$ across all individuals showed a unimodal pattern with a median and mode of zero, it was not normally distributed when analysed for both sexes separated and pooled using the Shapiro-Wilk $W$-test (JMP 3.1.5). The deviation from normality was mainly due to left skew in the distribution, pointing towards a directional asymmetry component. When tested across the three predetermined areas (Mediterranean core, ecotone and arid periphery), the deviation of the signed $\mathrm{R}-\mathrm{L}$ distribution median from zero was significant for both the ecotone and the periphery (with a Wilcoxon signed-rank statistic of $-165.5, P<0.01$ and $-376.5, P<0.01$, respectively) but not for the Mediterranean core. Skewness of the distribution was significant at the periphery of the range $(0.8344 ; \mathrm{SE}=0.2722 ; P<0.001)$. Thus, a shift in the distribution and asymmetry pattern was apparent from core to periphery across the chukar range in Israel (Kark, 1999).

\section{Discussion}

Heterozygosity and bilateral asymmetry were not significantly associated at either the population or the individual levels along a steep distribution cline in Israel. Similar results were found when each population was analysed separately or when all populations were combined. Genetic diversity, as estimated by the levels of both observed and expected heterozygosity, showed very different spatial patterns from those seen for bilateral asymmetry across the range. Whereas mean observed and expected heterozygosity showed a humpshaped pattern from core to periphery, peaking at the transitional Mediterranean-desert ecotone, bilateral asymmetry increased monotonically from the core towards the periphery, with an abrupt step at the ecotone. The differences in asymmetry vs. heterozygosity patterns across the distribution range are exemplified by the two geographically closest populations in the sample, Yatir, where mean annual rainfall is over $300 \mathrm{~mm}$, and Hirbet Sira, with approximately $200 \mathrm{~mm}$ rainfall. Located across a sharp climatic gradient, only several $\mathrm{km}$ away from each other in the ecotone region of the northern Negev, a steep decline in the percentage of symmetrical individuals occurred between the two populations (Table 1). Mean levels of unsigned $\mathrm{R}-\mathrm{L}$ 
changed from 0.026 in Yatir to 0.070 in Hirbet Sira. However, the two had a similar genetic structure and heterozygosity levels (Table 1).

Fluctuating asymmetry has been suggested as a useful tool in evaluating the degree of environmental and genetic stress to which individuals are subject during development (Møller \& Swaddle, 1997 and references therein). Yet, based on our findings, although it may potentially serve as a useful approach for estimating levels of environmental stress, it may not be a widely applicable tool for estimating genetic stress. This work suggests that even within a single species' range and across relatively short distances, there may be different associations between asymmetry and levels of heterozygosity. In addition, this study emphasizes the importance of a more detailed sampling of the range for understanding spatial patterns in both diversity and asymmetry. In the chukar case, partial sampling of the range, from the core towards the ecotone or from the ecotone towards the periphery exclusively, may have led to different conclusions as to the relationship between genetic diversity and developmental instability (see Fig. 2b,c). In both cases the correlation was not statistically significant yet the correlation direction changed. Siikämaki \& Lammi (1998) have found that asymmetry in the flowers of an annual plant species (Lychnis viscaria) in Finland was higher in marginal compared with core populations. The latter populations had higher levels of heterozygosity. Yet when the plants were grown under common-garden conditions rather than their original environment, the differences in asymmetry between margin and core and the association between asymmetry and heterozygosity both disappeared (Siikämaki \& Lammi, 1998). The authors suggested that due to interactions between genetic and environmental stresses, the effect of genetic variability on asymmetry may be apparent only when some other environmental stress is acting (Siikämaki \& Lammi, 1998). It appears that certain factors (e.g. population size) may lead to similar predictions as to spatial patterns in symmetry and in genetic diversity across a distributional gradient, yet this does not necessarily express a direct or causal relationship between the two. Mulvey et al. (1994) studied asymmetry levels and fitness in relation to heterozygosity classes in Gambusia holbrooki reared at normal vs. high temperatures. They showed that a strong and significant correlation between asymmetry and heterozygosity occurred only under stressful conditions. In a non-stressful environment this relationship, though negative, was weak and was nonsignificant. They suggested that differences in performance among individuals with different heterozygosity levels and genotypes occurs only under environmentally stressful conditions (see Mulvey et al., 1994). Based on this logic, it could be predicted that the direction of the association between asymmetry and genetic diversity will shift in different sections of the distribution range and that asymmetry and genetic diversity will be negatively correlated only beyond a certain threshold of stress. Indeed, a negative relationship between asymmetry and genetic diversity is apparent in this study only in the section beyond the Mediterranean-arid ecotone threshold, towards the margins of the range. Yet further analysis of the data suggests that there is no significant correlation between allozyme diversity and asymmetry when analysed for each of the populations at either the periphery or the centre of the range. Thus, a negative association between diversity and asymmetry did not appear in marginal parts of the distribution where populations are smaller and more isolated.

We suggest that it is rather more likely that different factors are shaping the spatial trends of bilateral asymmetry and of allozyme heterozygosity across the distribution range. In some cases their effects may coincide, resulting in an apparent direct relationship between asymmetry and heterozygosity. We believe that a more detailed and continuous sampling of the range, from the very extreme periphery to the interior of the range can reveal spatial patterns that were previously overlooked, and may lead to a better understanding of the underlying mechanisms and spatio-temporal dynamics of asymmetry and of genetic diversity.

An implicit assumption in various studies testing the relationship between asymmetry and heterozygosity is that the latter represents the genome-wide levels of genetic stress. However, when empirically tested, studies focus on a selected subsample of loci, usually of allozymes, and in most cases the degree to which these actually represent genome-wide phenomena remains unknown. In this study 26 allozyme loci were examined, of which nine were polymorphic. It could well be that the heterozygosity observed in these loci does not represent a genome-wide pattern, and that the relationship would be different for other markers (e.g. microsatellites). Previous work focusing on allozyme diversity and heterozygosity across the chukar partridge range in Israel has revealed substantial genetic structuring in chukar populations across short geographical distances and in the face of high levels of gene flow (Kark et al., 1999). This suggests that selection may be influencing allozyme heterozygosity levels at these specific loci. Thus the relationship between the observed heterozygosity and the genomewide heterozygosity may partly depend on the set of loci studied. Further work comparing a wide range of genetic markers (especially selected vs. unselected) and different populations across the distribution range may help us better understand the relationship between 
environmental and genetic stress and their association with developmental instability.

\section{Acknowledgements}

Our thanks to S. Clegg, L. Lens, D. Russel, S. Van Dongen and A. Wilby for their helpful reviews of the manuscript, to the Israel Nature Conservation and National Parks Authority scientists and rangers for their assistance in field work, and to P. U. Alkon, R. Alford, G. M. Clarke, J. H. Graham, G. Livshits and I. NoyMeir for fruitful discussion. Support for this research was granted to S.K. from the Pontremoli and the Rieger Research Funds through Keren Kayemet LeIsrael (JNF), The Ecology Fund founded by the JNF, The Blaustein International Center for Desert Studies of the Blaustein Institute for Desert Research, Ben-Gurion University of the Negev and to E.R. from Istituto Nazionale per la Fauna Selvatica.

\section{References}

ALkon, P. U. 1974. Social Behavior of a Population of Chukar Partridge (Alectoris chukar) in Israel. PhD Thesis. Cornell University, Ithaca, NY.

ALKON, P. U. 1979. Gonadal cycles in a population of chukar partridge (Alectoris chukar) (Aves: Phasianidae). Israel J. Zool., 28, 167-176.

BITAN, A. AND RUBin, S. 1991. Climatic Atlas of Israel for Physical and Environmental Planning and Design. Ministry of Transport, Jerusalem.

BRITTEN, H. B. 1996. Meta-analysis of the association between multilocus heterozygosity and fitness. Evolution, 50, 2158-2164.

BROOKES, M. I., GRANEAU, Y. A., KING, P., ROSE, O. C. ET AL. 1997. Genetic analysis of founder bottlenecks in the rare British butterfly Plebejus argus. Conserv. Biol., 11, 648-661.

ClARKE, G. M. 1993. The genetic basis of developmental stability. I. Relationships between stability, heterozygosity and genomic coadaptation. Genetica, 89, 15-23.

ClARKE, G. M. 1995. Relationships between developmental stability and fitness: application for conservation biology. Conserv. Biol., 9, 18-24.

ClARKE, G. M. 1998. The genetic basis of developmental stability. IV. Individual and population asymmetry parameters. Heredity, 80, 553-561.

DANIN, A. AND PLITMAN, U. 1987. Revision of the plant geographical territories of Israel and Sinai. Pl. Syst. Evol. 156, 43-53.

DAVID, P., HINGLE, A., FOWLER, K. AND POMIANKOWSKI, A. 1999. Measurement bias and fluctuating asymmetry estimates. Anim. Behav., 57, 251-253.

GRAHAM, J. H., FREEMAN, D. C. AND EMLEN, J. M. 1993. Antisymmetry, directional asymmetry, and dynamic morphogenesis. Genetica, 89, 121-137.
GRAHAM, J. H., EMLEN, J. M., FREEMAN, D. C., LEAMY, L. J. ET AL. 1998. Directional asymmetry and the measurement of developmental instability. Biol. J. Linn. Soc., 64, 1-16.

KARK, S. 1999. Within-Population Diversity in the Distribution Range: Partridges as a Research Model. PhD Thesis. The Hebrew University of Jerusalem, Jerusalem and http:// www.stanford.edu/group/Mooney/salit

KARK, S., ALKON, P. U., SAFRIEL, U. N. AND RANDI, E. 1999. Conservation priorities for the chukar partridge in Israel based on genetic diversity across an ecological gradient. Conserv. Biol., 13, 542-552.

KAT, P. W. 1982. The relationship between heterozygosity for enzyme loci and developmental homeostasis in peripheral populations of aquatic bivalves (Unionidae). Am. Nat., 119, 824-832.

LEARY, R. F. AND ALLENDORF, F. W. 1989. Fluctuating asymmetry as an indicator of stress: implications for conservation biology. Trends Ecol. Evol., 4, 214-217.

LEARY, R. F., ALlENDORF, F. W. AND KNUDSEN, K. L. 1985. Developmental instability and high meristic counts in interspecific hybrids of salmonid fishes. Evolution, 39, 1318-1326.

LERNER. 1954. Genetic Homeostasis. Oliver \& Boyd, Edinburgh. LIVSHITS, G. AND SMOUSE, P. E. 1993a. Fluctuating asymmetry as a possible measure of developmental homeostasis in humans: a review. Genetica, 89, 155-166.

LIVSHITS, G. AND SMOUSE, P. E. 1993b. Multivariate fluctuating asymmetry in Israeli adults. Human Biol., 65, 547-578.

Ludwig, w. 1932. Das rechts-links Problem im Tiereich und beim Menschen. Springer, Berlin.

MARKOW, T. A. 1995. Evolutionary ecology and developmental instability. Ann. Rev. Entomol., 40, 105-120.

MAYr, E. 1970. Populations, Species, and Evolution. Belknap Press, Cambridge, MA.

MøLleR, A. P. 1998. Developmental stability as a general measure of stress. In: Møller, A. P., Milinski, M. and Slater, P. J. B. (eds) Advances in the Study of Behavior, vol. 27, pp. 181-213. Academic Press, London.

Møller, A. P. AND SWADdle, J. P. 1997. Asymmetry, Developmental Stability, and Evolution. Oxford University Press, Oxford.

MUlVeY, M., Keller, G. P. AND MEFFE, G. K. 1994. Single- and multiple-locus genotypes and life-history responses of Gambusia holbrooki reared at two temperatures. Evolution, 48, 1810-1819.

PALMER, A. R. 1994. Fluctuating asymmetry analyses: a primer. In: Markow, T. A. (ed.) Developmental Instability: Its Origin and Evolutionary Implications, pp. 335-364. Kluwer Academic Publishers, Dordrecht.

PALMER, A. R. AND STROBECK, C. 1986. Fluctuating asymmetry: measurement, analysis, patterns. Ann. Rev. Ecol. Syst, 17, 391-421.

RANDI, E. AND ALKON, P. U. 1994. Genetic structure of chukar partridge populations in Israel. The Auk, 111, 416-426.

RICE, W. R. 1989. Analyzing tables of statistical tests. Evolution 43, 223-225.

ShIRIHAI, H. 1996. The Birds of Israel. Academic Press, London. 
SIIKÄMAKI, P. AND LAMMI, A. 1998. Fluctuating asymmetry in central and marginal populations of Lychnis viscaria in relation to genetic and environmental factors. Evolution, 52, 1285-1292.

SWADDLE, J. P. AND CUTHILl, I. C. 1994. Preference for symmetric males by female zebra finches. Nature, 367, 165-166.

SWADDLE, J. P., WITTER, M. S. AND CUTHILl, I. C. 1994. The analysis of fluctuating asymmetry. Anim. Behav. 48, 986-989.

SWOFFORD, D. L. AND SElANDER, R. K. 1989. Biosys-1. A computer program for the analysis of allelic variation in population genetics. Release 1.7. University of Illinois, Urbana, IL.

VAN VALEN, L. 1962. A study of fluctuating asymmetry. Evolution, 16, 125-142.

vøllestad, L. A., HiNDAR, K. AND MøLleR, A. P. 1999. A metaanalysis of fluctuating asymmetry in relation to heterozygosity. Heredity, 83, 206-218.

woolf, C. M. 1993. Does homozygosity contribute to the asymmetry of common white leg markings in the Arabian horse? Genetica, 89, 25-34. 